\title{
Markers' influence on the duration discrimination of intermodal intervals
}

\author{
SIMON GRONDIN \\ Université Laurentienne, Sudbury, Ontario, Canada \\ RICHARD B. IVRY and ELIZABETH FRANZ \\ University of California, Berkeley, California \\ and \\ LYNN PERREAULT and LYNN METTHÉ \\ Université Laurentienne, Sudbury, Ontario, Canada
}

\begin{abstract}
The effects of sensory signal characteristics on the duration discrimination of intermodal intervals was investigated in three experiments. Temporal intervals were marked by either the successive presentation of a visual then auditory signal (VA), or by the successive presentation of an auditory then visual signal (AV). The results indicated that (1) VA intervals are generally easier to discriminate than are AV intervals, but this effect depends on the range of duration studied; (2) AV intervals are perceived as longer than VA intervals for durations ranging from 250 to $750 \mathrm{msec}$; (3) the intensity of the visual markers for both $\mathrm{AV}$ and VA intervals does not affect the discrimination; and (4) the perceived duration of an intermodal interval is influenced by the length of the first and second markers. The results are mainly interpreted in terms of (1) a sensory trace left by visual and auditory signals and (2) the detection of these signals.
\end{abstract}

The objective of the present series of experiments was to study how the perception of duration is influenced by the markers used to bound an interval. The intervals in these studies are called empty because we vary the duration of a silent interval separated by the two markers that indicate the beginning and end. When the markers are produced by the same sensory mode, the interval is intramodal. If the sensory mode of the markers is different, the interval is intermodal.

Time perception research has been dominated by the use of intramodal markers. For example, numerous studies have compared temporal acuity for intervals marked by a pair of auditory or visual signals (Abel, 1972; Carpotte \& Kristofferson, 1973; Divenyi \& Danner, 1977; Divenyi \& Sachs, 1978; Nilsson, 1969; Penner, 1976). Less studied has been the perception of intervals marked by intermodal signals.

This research was supported by a grant from the Natural Sciences and Engineering Research Council of Canada to S.G., a grant from the National Institutes of Health to R.B.I., and a Summer Scholarship to L.P. and L.M. from NSERC. We wish to thank S. Koren for his technical assistance, and N. Macmillan, P. Killeen, and an anonymous reviewer for their comments on a previous draft of this article. Portions of the material included in this article were presented at the 34th Annual Meeting of the Psychonomic Society, held in Washington in 1993, and other portions were presented at the Fourth Annual Meeting of the Canadian Society for the Study of Brain, Behaviour and Cognitive Science, held in Vancouver in 1994. Correspondence should be addressed to S. Grondin, École de psychologie, Université Laval, Québec, PQ, Canada G1K 7P4.
Accuracy in judging the duration of an empty intramodal interval is generally found to be minimally affected by the sensory characteristics of the markers (Allan, 1979). This fact indicates that those time judgments are based on a timing mechanism that operates independently of the sensory properties of the markers. Indeed, the literature on human duration discrimination offers theoretical explanations based on the assumption that there is a central, single timer whose variability is said to be the main source of discrimination errors (Allan \& Kristofferson, 1974; Creelman, 1962; Divenyi \& Danner, 1977; Ivry, 1993; Keele \& Ivry, 1991; Killeen \& Weiss, 1987; Treisman, 1963). However, the temporal judgments are much more difficult when intervals are intermodal instead of intramodal (Collyer, 1974; Fraisse, 1952; Grondin \& Metthé, 1993; Grondin \& Rousseau, 1991; Rousseau, Poirier, \& Lemyre, 1983). The present experiments describe some of the effects of intermodal markers on duration discrimination.

The different levels of performance reached in intraand intermodal conditions remain an elusive problem for researchers interested in a single-timer hypothesis. In the present paper, we describe an empirical investigation of the perception of intermodal intervals in order to gain better knowledge of the variables that influence the discrimination of such intervals. Our initial objective is to investigate two main issues: (1) Is intermodal performance dependent on the order of the two signals? To assess this, we compared performance with intervals marked by the succession of a visual and an auditory signal (VA) with those marked by the succession of an auditory and a vi- 
sual signal (AV). (2) If there is an order effect, can it be attributed to differences in processing the markers? For example, perhaps there is an asymmetry in the forward masking properties of auditory and visual signals. For example, an initial visual signal may produce intermodal "forward masking" on a following auditory signal. To explore this issue, we varied the intensity of the visual signal in both the AV and the VA conditions.

\section{EXPERIMENT 1}

\section{Method}

Subjects. Six subjects, between 19 and 33 years old, participated in this experiment. Five subjects were female volunteers paid $\$ 42$ (Canadian); 4 of them were Laurentian University students, and the other was a well-trained subject. The 6th subject was S.G.

Apparatus and Stimuli. The subjects were seated in a chair in a dark room. They were asked to judge the length of an interval defined by the end of a first marker and the beginning of a second marker, and to respond either "short" or "long" by pressing one of two response buttons. Adjacent to each button was a small light providing feedback after each trial. The auditory signal, presented binaurally, was a $1-\mathrm{kHz}$ tone with an intensity recorded at $70 \mathrm{~dB}$ SPL. The visual signal consisted of a circular light-emitting diode (LED) situated at about $1 \mathrm{~m}$ in front of the subject. Both auditory and visual markers were $20 \mathrm{msec}$ in duration. There were two levels of visual intensity. The red LED (Radio Shack No. 276-088) is manufactured to reach a maximum of $500 \mathrm{mcd}$ with a $20-\mathrm{mA}$ current. Currents of $2.1 \mathrm{~mA}$ (high intensity: $V_{H}$ ) and $0.8 \mathrm{~mA}$ (low intensity: $V_{L}$ ) were used. Both were clearly detectable. ${ }^{1}$

Procedure. A forced-choice adaptive procedure was used. Each trial consisted of the presentation of a standard interval and a comparison interval. The order of the two intervals was counterbalanced. The subject indicated by pressing the appropriate button, whether the first interval was shorter or longer than the second interval. Each empty interval was marked by two 20 -msec signals. The first and the second intervals were separated by a 1 -sec interval. Following each response, the feedback signal ( 2 mcd red LED) located next to the correct response key was illuminated for $1.7 \mathrm{sec}$. The next trial started $2 \mathrm{sec}$ after the termination of the feedback signal.

Three different durations for the standard interval were tested. These were 250,500 , and $750 \mathrm{msec}$. The duration of the comparison interval was adjusted after each trial. Specifically, after each correct response, the duration of the comparison interval was made more similar to that of the standard interval by a factor of $X$, and, after each incorrect response, the duration of the comparison interval was made more different than the standard interval by a factor of $3 \mathrm{X}$. This technique, a weighted up-down method, provides an estimate of the difference threshold at which subjects are correct on $75 \%$ of the trials (Kaernbach, 1991; Rammsayer, 1992b).

Each threshold estimate was based on a run of 50 trials. These 50 trials were composed of three blocks of 10,20 , and 20 trials. Within each block, adjustment step size (X) was held constant, and between blocks, the step size was decreased. The duration of the first comparison interval and the step sizes are reported in Table 1. The adjustment procedure was constrained so that the duration of the comparison interval could not be smaller than or equal to the duration of the standard interval. Thus, there were instances in which the duration of the comparison interval was identical for successive trials.

For each subject, there were 12 sessions, one for each experimental condition: 3 standards $\times 4$ marker types $\left(A V_{H}, A V_{L}, V_{H} A\right.$, $V_{L} A$ ). In each session, estimates of the difference thresholds were obtained from four runs of 50 trials each. The average of the three lowest thresholds was used in the analysis. At the beginning of the
Table 1

Size of Steps for Each Standard and Group of Trials With the Adaptative Procedure of Experiment 1

\begin{tabular}{crrr}
\multicolumn{4}{c}{ With the Adaptative Procedure of Experiment 1 } \\
Trial Group & \multicolumn{3}{c}{ Standard } \\
\hline $1-10$ & 250 & 500 & 750 \\
$11-30$ & 10 & 50 & 75 \\
$31-50$ & 3 & 15 & 20 \\
First comparator & 375 & 4 & 5 \\
\hline
\end{tabular}

Note - All standards and scores are in milliseconds.

first session, practice trials were provided to make sure that the subjects understood the task.

\section{Results}

The results generally indicated a very slight effect of intensity, and a lower difference threshold, for the 500 and $750-\mathrm{msec}$ conditions in the VA condition than in the AV condition. Table 2 shows the difference thresholds for each condition averaged over subjects. The difference between the means was tested with a randomized block factorial analysis of variance (ANOVA) (2 marker types $\times 2$ visual intensities $\times 3$ durations; Kirk, 1982).

We observed a significant effect of duration $[F(2,60)=$ $24.58, p<.01\}$, and, more interestingly, a difference between $\mathrm{AV}$ and the VA performances $[F(1,60)=6.67, p<$ $.05]$. The latter effect was most evident when the duration of the standard interval was either 500 or $750 \mathrm{msec}$. For these durations, the difference threshold was clearly smaller in the VA conditions than in the AV conditions. Although the results at $250 \mathrm{msec}$ do not show this pattern, there was no significant interaction between duration and marker order $[F(2,60)=.99, p=.38]$.

No significant differences were found as a function of the intensity of the visual signal $[F(1,60)=.05, p=.82]$. Although there was a trend for subjects to perform more accurately with the high intensity at $250 \mathrm{msec}$, this factor did not interact with duration. Similar null results have been reported (Allan, Kristofferson, \& Wiens, 1971; Carbotte \& Kristofferson, 1973; Nilsson, 1969). More recently, Fetterman and Killeen (1992) reported that pigeons discriminate duration independently of the intensity of visual signals, and Rammsayer (1994) reported no effect of loudness on duration discrimination of very short filled auditory intervals. Note, however, that other researchers have found that the physical characteristics of the mark-

Table 2

Mean Differential Threshold in Each Condition of Experiment 1

\begin{tabular}{|c|c|c|c|c|}
\hline \multirow[b]{3}{*}{ Duration } & \multicolumn{4}{|c|}{ Condition } \\
\hline & \multicolumn{2}{|c|}{ Auditory-Visual } & \multicolumn{2}{|c|}{ Visual-Auditory } \\
\hline & $\begin{array}{c}\text { Low } \\
\text { Intensity }\end{array}$ & $\begin{array}{l}\text { Medium } \\
\text { Intensity }\end{array}$ & $\begin{array}{c}\text { Low } \\
\text { Intensity }\end{array}$ & $\begin{array}{l}\text { Medium } \\
\text { Intensity }\end{array}$ \\
\hline 250 & 59 & 50 & 54 & 50 \\
\hline 500 & 65 & 77 & 58 & 51 \\
\hline 750 & 96 & 102 & 79 & 87 \\
\hline
\end{tabular}

Note-All values are in milliseconds. 
ers of empty auditory intervals can influence acuity (e.g., Divenyi \& Danner, 1977; Grondin \& Rousseau, 1991).

\section{Discussion}

The finding that duration discrimination is affected by marker order has been previously observed by Rousseau et al. (1983) for intervals of 925 and $1,075 \mathrm{msec}$. In that study, the duration of VA intervals was generally found to be easier to discriminate than was the duration of $\mathrm{AV}$ intervals. The present findings demonstrate that this effect is also found for shorter intervals.

To account for this phenomenon, it is useful to consider how the markers may influence the internal representation of the interval. Our instructions emphasized that subjects should judge the duration between the offset of the first stimulus and the onset of the second stimulus, that is, the empty interval bounded by the two sensory signals. This would imply that the timing of the interval begins as soon as the subject is able to detect the offset of the initial marker. Similarly, the end of the interval will correspond to the point at which the subject detects the onset of the second marker. Thus, the perceived duration of the interval will depend on the subjects' ability to detect these changes in the sensory signals.

There is evidence in the literature indicating that this ability will differ for the two modalities. Considering the time to detect the onset of a signal, the evidence consistently shows that auditory signals are detected more rapidly than are visual signals (Giray \& Ulrich, 1993; Keele, 1986). The time to detect the offset of these signals has received less atttention. However, the literature suggests considerable persistence following the offset of a brief visual signal (Nisly \& Wasserman, 1989). Given the auditory system's high sensitivity to rapidly changing signals (see, e.g., Tallal, Miller, \& Fitch, 1993), it seems reasonable to assume that the detection of the offset is longer in the visual mode than in the auditory mode.

Consider how these two effects would distort the internal representation of an empty interval. Since the activation of the timing mechanism is assumed to be triggered when the sensory trace of the first marker fades, the onset of timing of VA intervals will be delayed in comparison to that of AV intervals. In contrast, termination of the timer is dependent on detecting the second marker. This will occur earlier for VA intervals than for AV intervals. The combined result of these two asymmetries will produce a shorter internal representation of the VA interval than the AV interval (Figure 1). In other words, there are two reasons to assume that an AV interval is perceived as longer than a VA interval. This explanation regarding the timing of empty intervals has been applied previously to account for why empty intervals are easier to discriminate than are filled intervals (Grondin, 1993).

To account for how this asymmetric representation will affect discrimination acuity, we need to consider how the well-established Weber's law can apply to duration perception. This law describes the relation between two physical quantities, a difference threshold and a

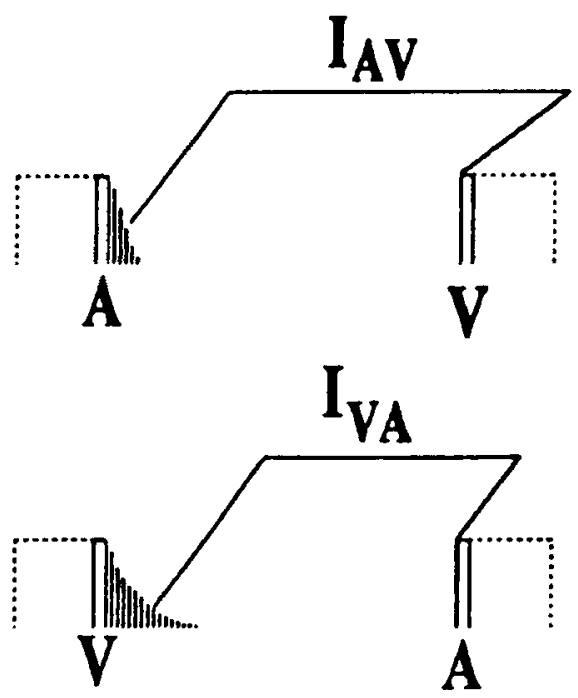

Figure 1. Schematic of the infernal-marker hypothesis applied to the comparison of the auditory-visual (AV) and visual-auditory (VA) intervals. Although the physical offset of the first marker ( $A$ in the upper panel and $V$ in the lower panel) and the physical onset of the second marker ( $V$ in the upper panel and $A$ in the lower panel) are separated by the same physical duration, the internal duration marked by the $A$ and $V$ signals $\left(I_{A V}\right)$ is longer than the internal duration marked by the $V$ and $A$ signals $\left(I_{V A}\right)$. The points indicate that the physical duration of the first and the second marker can vary without changing the perceived intervals.

standard stimulus. However, time is not stricto sensu a physical stimulus and thus, we should be careful in how we apply Weber's law. Although the experimenter can control the actual duration of the stimuli, the perceived duration is an internal construct. In the perspective of time psychophysics, this construct is typically claimed to be based on pulses emitted by a pacemaker (Church, 1984; Creelman, 1962; Treisman, 1963). The period of accumulation of pulses, which eventually constitutes the duration, is determined by the internal marking activity (Allan et al., 1971). Physical stimuli serving to mark the passage of time, whether auditory, visual, or tactile, are internally transmitted to define the period of pulses' accumulation. It is this internal period that represents the stimulus, and it is reasonable to suppose that Weber's law should be evaluated on the basis of this representation rather than on that of the external duration. Note that in most studies of duration perception, the marker conditions are held constant. If the effects of the markers are constant, then proportional changes in the difference threshold as duration increases will hold for both physical duration and the internal representation of these durations. However, if the marking conditions are manipulated and these produce systematic distortions in perceived duration, then there would not be a correspondence between physical time and perceived duration. In the case of the AV versus VA comparison, we have argued that the period of accumulation of pulses is not the same (Figure 1) and results in a systematic distortion. Weber's law states that a shorter perceived duration should yield a 
lower difference threshold. This appears to be the case in the present experiment. The internal-marker hypothesis predicts that VA intervals are perceived as shorter than $\mathrm{AV}$ intervals, and correspondingly, the difference thresholds for the former condition are smaller.

The proposal to link the difference threshold to subjective duration rather than to physical time is not new. Nakajima (1987) proposed such an idea for the discrimination of empty intervals, extending an earlier conjecture by Ekman (1959).

It should be noted that the preceding discussion was premised on the assumption that subjects mark the interval as directed by the instructions. It is also possible that, rather than timing the interval bounded by the two markers, subjects may be forming an internal representation based on the interval separating the onset of both signals. Nonetheless, onset-to-onset timing would also be expected to produce a distortion in which $\mathrm{AV}$ intervals are perceived as longer than VA intervals. In this case, the shorter latency to trigger the timing process by auditory signals would apply for both markers. The following experiment was designed to determine whether the timing of cross-modal intervals is triggered by the offset or onset of the first marker.

\section{EXPERIMENT 2}

Three issues were addressed in Experiment 2. First, we sought to replicate the finding that discrimination is better with VA intervals than with AV intervals. Second, we tested the prediction that VA intervals are perceived as shorter than are AV intervals. To accomplish this, we used a psychophysical procedure that allowed estimates of both the point of subjective equality (PSE) as well as difference thresholds.

Third, we manipulated the duration of the first marker, reasoning that this manipulation should help determine whether empty intervals are timed from the offset of the initial marker or from the onset of the first marker (Penner, 1976). If the subject is able to follow the instructions and begin timing the intervals at the offset of the first marker, then increasing the duration of this marker should not affect performance. However, if timing is initiated at the onset of the first marker, then increasing the duration of the first marker should produce a corresponding increase in perceived duration. Using intramodal auditory intervals, Woodrow (1928) reported that intervals were judged as longer when the duration of the first marker was increased. The following experiment explored the generality of this effect.

\section{Method}

Subjects. Four subjects, one 42-year-old male and three female Laurentian University students, between 19 and 22 years old, participated in the 15 sessions of this experiment. They were paid $\$ 60$ (Canadian).

Apparatus and Stimuli. The apparatus was similar to that described for Experiment 1. The auditory stimulus was the same as that in Experiment 1, and the intensity of the visual signal was in- creased by using a current of $12.2 \mathrm{~mA}$ (see note 1 ). The main difference was the length of the first marker: In the present experiment, the first marker was either a 5 - or a 100 -msec stimulus. The second marker was always $5 \mathrm{msec}$ in duration.

Procedure. The many-to-few procedure was adopted (Allan, 1979). The subject judged whether the interval presented was "short" or "long." A 1.7-sec feedback signal was presented $200 \mathrm{msec}$ after the response, followed by a $1-\mathrm{sec}$ intertrial interval. The feedback indicated if the presented interval (see below) was one of the two shorter intervals (short category) or one of the two longer intervals (long category). Before each trial, the subject did not know the identity of the markers (AV or VA) or the duration of the first marker ( 5 or $100 \mathrm{msec}$ ). There were four marker conditions: $V_{5} A, V_{100} A, A_{5} V$, and $A_{100} V$. The subject was instructed to discriminate the durations between the end of the first signal and the beginning of the second signal.

As in Experiment 1, there were three standard durations of 250 , 500 , and $750 \mathrm{msec}^{2}$ Note that these durations refer to the amount of time between the end of the first signal and the onset of the second signal (interstimulus intervals) and not the times from the onset of Marker 1 to the onset of Marker 2 (stimulus-onset asynchronies). For each of these conditions, four intervals were presented: Two were shorter than the standard, and two were longer. For the three durations, the length of those intervals was 190, 230, 270 , and $310 \mathrm{msec} ; 380,460,540$, and $620 \mathrm{msec}$; and 570,690 , 810 , and $930 \mathrm{msec}$. Those values were selected on the basis of performances in other experiments involving AV and VA conditions with a 250 -msec standard. We determined the test values for the 500 -msec and $750-\mathrm{msec}$ conditions by multiplying the 250 -msec values by 2 and by 3 , respectively.

There were 15 sessions divided into 3 parts of 5 , one for each standard duration. The first session of each part was a training session and was divided into six blocks of 64 trials. Each of the first four blocks was devoted to only one marker condition. The last two blocks were as in the experimental sessions, that is, with a randomization from trial to trial of the marker conditions. In the experimental sessions $(2-5,7-10$, and $12-15)$, there were six identical blocks of 64 trials involving on a random basis, the four durations and the four marker conditions. Each of those 16 possibilities was presented four times within a block. Thus, over the experimental sessions, each datum on the 4-point psychometric function for each marker condition was based on 96 presentations (four per block; six blocks per session; four sessions).

\section{Results}

For each of the 12 experimental conditions ( 2 marker orders $\times 2$ Marker 1 lengths $\times 3$ durations), and for each subject, a 4-point psychometric function was traced, plotting the four comparison intervals from short to long on the $X$ axis, and the $Z$ transformation of the probability of responding "long" on the $Y$ axis. Psychometric functions were estimated on the basis of linear regression. Durations corresponding to $25 \%(Z=-.67)$ and $75 \%(Z=.67)$ of "long" responses were calculated. The difference, divided by 2 , was the difference threshold. These two points, $25 \%$ and $75 \%$, represent the midpoint between a zero level of discrimination $(50 \%)$ and a perfect level of discrimination $(100 \%$ and $0 \%)$. The PSE $^{3}$ is the estimated duration corresponding to $50 \%$ of "long" responses.

Table 3 shows the individual and averaged difference thresholds for each of the 12 experimental conditions. For each length of Marker 1, the mean difference threshold in the VA condition was lower than that in the AV 
Table 3

Differential Threshold (DT) and Point of Subjective Equality (PSE) Under Each Experimental Condition of Experiment 2

\begin{tabular}{|c|c|c|c|c|c|c|c|c|c|c|c|c|c|}
\hline \multirow[b]{3}{*}{ Subject } & & \multicolumn{6}{|c|}{ Auditory-Visual } & \multicolumn{6}{|c|}{ Visual-Auditory } \\
\hline & & \multicolumn{3}{|c|}{5} & \multicolumn{3}{|c|}{100} & \multicolumn{3}{|c|}{5} & \multicolumn{3}{|c|}{100} \\
\hline & & 250 & 500 & 750 & 250 & 500 & 750 & 250 & 500 & 750 & 250 & 500 & 750 \\
\hline \multirow[t]{2}{*}{1} & DT & 36 & 67 & 77 & 52 & 67 & 91 & 34 & 47 & 87 & 36 & 56 & 84 \\
\hline & PSE & 268 & 458 & 717 & 197 & 464 & 755 & 322 & 551 & 784 & 239 & 486 & 710 \\
\hline \multirow[t]{2}{*}{2} & DT & 47 & 56 & 114 & 40 & 48 & 106 & 95 & 25 & 88 & 99 & 51 & 86 \\
\hline & PSE & 258 & 438 & 661 & 242 & 474 & 649 & 444 & 564 & 818 & 212 & 472 & 745 \\
\hline \multirow[t]{2}{*}{3} & DT & 49 & 93 & 98 & 110 & 133 & 111 & 60 & 73 & 90 & 78 & 116 & 105 \\
\hline & PSE & 195 & 459 & 682 & 146 & 445 & 741 & 297 & 551 & 722 & 234 & 487 & 697 \\
\hline \multirow[t]{4}{*}{4} & DT & 79 & 122 & 110 & 84 & 170 & 199 & 170 & 74 & 107 & 66 & 112 & 114 \\
\hline & PSE & 291 & 558 & 818 & 164 & 362 & 772 & 580 & 620 & 757 & 290 & 483 & 707 \\
\hline & Mean DT & 53 & 85 & 100 & 72 & 105 & 127 & 90 & 55 & 93 & 70 & 84 & 98 \\
\hline & Mean PSE & 253 & 478 & 720 & 187 & 436 & 729 & 411 & 571 & 770 & 244 & 482 & 715 \\
\hline
\end{tabular}

Note-All values are in milliseconds

condition at 500 and $750 \mathrm{msec}$. At $250 \mathrm{msec}$, discrimination appeared to be easier in the $\mathrm{AV}$ condition than in the VA condition, at least when the initial marker was $5 \mathrm{msec}$ in duration.

The difference between the means for those differential thresholds was tested with a randomized factorial block ANOVA ( 2 marker orders $\times 2$ Marker 1 lengths $\times$ 3 durations). A significant effect of duration was obtained $[F(2,33)=7.40, p<.01]$, and there was no significant effect on Marker 1 length $[F(1,33)=3.41, p=.074]$. That there was no difference in thresholds when the first marker was $5 \mathrm{msec}$ compared with when it was $100 \mathrm{msec}$ suggests that discrimination is independent of the characteristics of the markers.

The main effect of marker order was not significant $[F(1,33)=1.41, p=.244]$, but this factor interacted with duration $[F(2,33)=3.33, p<.05]$. This marker order $\times$ duration interaction indicates that the difference threshold was lower for VA intervals than for AV intervals, but only for the longer durations. These results are consistent with the tendency observed in Experiment 1 (Table 2). None of the other interactions were significant.

The individual and averaged PSE are also shown in Table 3. The results generally show that the PSE was higher for the VA than for the AV condition. Moreover, the PSEs were greater when Marker 1 was $5 \mathrm{msec}$ in duration compared with $100 \mathrm{msec}$. This effect was more pronounced in the VA condition. Averaged over the three durations, the difference between the 5- and 100-msec conditions was $16.7 \mathrm{msec}$ in the AV condition and $51.8 \mathrm{msec}$ in the VA condition. It should be noted that for each duration, the PSE in the $V_{100} A$ condition was close to the one in the $\mathrm{A}_{5} \mathrm{~V}$ condition. This can be seen in Figure 2.

Before turning to the statistical analyses, one clarification of PSE should be emphasized. A smaller PSE means an upward shift of the psychometric function caused by a tendency to respond "long" more often. Consequently, the smaller the PSE, the longer the perceived duration. Moreover, to allow comparisons across the different durations, the obtained PSE scores were transformed by subtracting the implicit standard interval. ${ }^{4}$ Without this transformation, there would be an obvious main effect of duration, a result of no theoretical interest. The transformation allows an assessment of the relative effects of marker order and marker length across the different durations.

The ANOVA of the transformed scores revealed a main effect of marker order $[F(1,33)=18.45, p<.01]$ and of Marker 1 length $[F(1,33)=20.47, p<.01]$. The duration effect was not significant $[F(2,33)=2.62, p=$ $.088]$. The marker order and Marker 1 interaction was significant $[F(1,33)=5.50, p<.05]$. The duration $\times$ marker order interaction was not significant $[F(2,33)=$ $2.90, p=.069]$ nor was there a significant interaction of duration $\times$ Marker 1 length $[F(2,33)=3.18, p=.055]$. The triple interaction was also not significant $(p=.764)$.

\section{Discussion}

The noneffect of the marker length on the difference threshold is consistent with the findings of Rousseau and Kristofferson (1973). They reported no effect of the length of a visual marker $(10,500$, or $4,000 \mathrm{msec})$ for discrimination acuity in judging a VA interval of $100 \mathrm{msec}$. However, it should be noted that Rammsayer (1992a) reported a higher difference threshold for the discrimination of very brief empty auditory intervals when both markers lasted $300 \mathrm{msec}$ rather than 3 or $30 \mathrm{msec}$. Penner (1976), also reporting data for empty auditory intervals, noted that the randomization of the duration of the first marker influenced the discrimination.

VA intervals were perceived as shorter than $\mathrm{AV}$ intervals. This effect is in accord with the predictions derived from the analysis of the differences in the times required to detect either the onset or offset of the markers. However, the length of the first marker also influenced perceived duration. Intervals initiated by a 100 -msec marker were perceived as longer than intervals initiated with a 5-msec marker. This finding suggests that the temporal processing of a short intermodal interval is not independent of the characteristics of the first marker. Despite our instructions, which emphasized that subjects should judge the interval between the two markers, the results 

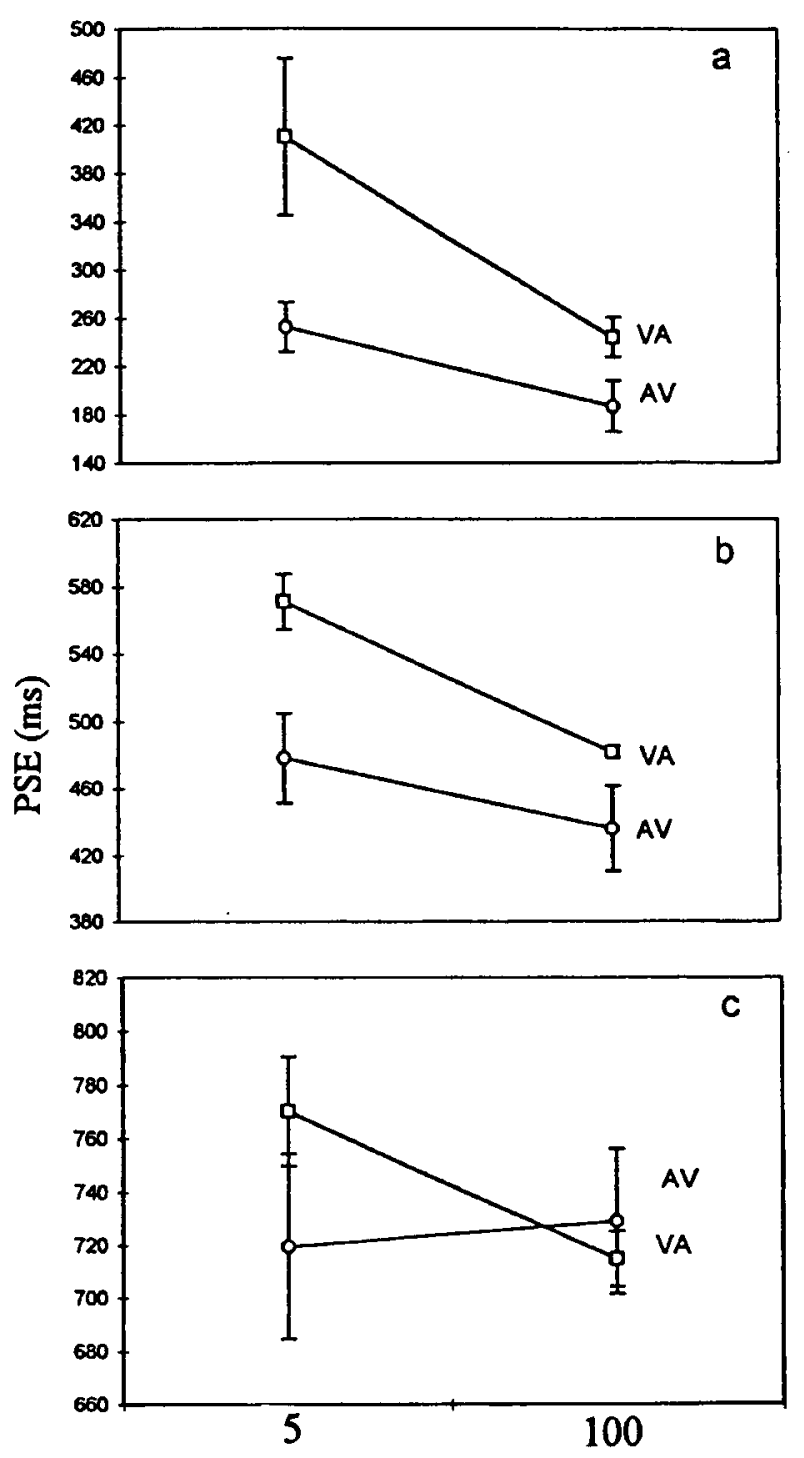

Length of Marker 1 (ms)

Figure 2. Mean point of subjective equality (PSE) as a function of the length of Marker 1 for each marker condition of Experiment 2. The implicit standards are 250 (a), 500 (b), and 750 msec (c).

suggest that the timing process might have been initiated at the onset of the first marker. These findings are in accord with those reported by Woodrow (1928).

The magnitude of the effects of marker order and marker length is even more compelling given that the subjects were provided with feedback throughout the experiment. It might have been expected the feedback would have enabled subjects to adopt strategies to "compensate" for the asymmetries imposed by the different conditions. Although this may have occurred, the differences in PSE were quite substantial, especially in the VA condition. Indeed, it is important to note that these marker order and marker length effects interacted. The marker length effect applies in the VA condition, but not in the AV condition.

Taken together, the results of Experiment 2 reveal a few interesting features regarding the representation of cross-modal intervals. As in Experiment 1, the difference threshold was lower for VA intervals than for AV intervals, at least for intervals greater than $250 \mathrm{msec}$ in duration. It was proposed in the discussion of Experiment 1 that this effect reflects the fact that the internal representation of VA intervals is shorter than that of $\mathrm{AV}$ intervals, and, following Weber's law, the difference threshold should also be smaller. The results are in accord with this hypothesis. Given an interval of a fixed duration, subjects were more likely to judge it as longer in the AV condition than in the VA condition. However, the effects observed following the manipulation of the length of the initial marker were not consistent with this hypothesis. This manipulation produced reliable changes in the PSE but did not affect the difference thresholds. Finally, the present results convincingly demonstrate that the duration of the first marker has a substantial effect on the perceived duration of the interval marked by a VA sequence.

\section{EXPERIMENT 3}

In Experiment 3, we examined the effect on duration perception of empty intermodal intervals when the length of the second marker was varied. In our discussions to this point, it has been assumed that the timing of the intervals is terminated as soon as the second marker is detected. If this were so, it would be expected that varying the duration of the second marker would have no effect on PSE.

Woodrow (1928) reported mixed results for the effects of Marker 2 length on perceived duration for intramodal, auditory intervals. In one pair of experiments, a standard interval of $500 \mathrm{msec}$ was bounded by two 29 -msec markers. The comparison interval varied in duration and was marked by either a $50-\mathrm{msec}$ sound followed by an $8-\mathrm{msec}$ sound (long marker/short marker condition, or LS), or an 8-msec sound followed by a 50-msec sound (short marker/ long marker condition, or SL). Subjects showed a large bias toward judging the LS intervals as longer than the standard. For example, an LS interval of $500 \mathrm{msec}$ was judged long on $63.3 \%$ of the trials. The bias was the opposite for the SL intervals: an SL interval of $500 \mathrm{msec}$ was judged long on only $9.0 \%$ of the trials. (Woodrow used a different range for the two conditions, so direct comparisons must be made cautiously.) These data might lead to the expectation that lengthening the second interval might shorten perceived duration. However, the effects may simply be dictated by the difference in the length of the first marker.

In a final experiment, Woodrow (1928) used a standard bounded by two 6-msec sounds and a comparison interval initiated by a $6-\mathrm{msec}$ sound and terminated with a 38-msec sound. With this condition, increasing the du- 
ration of the second marker led to a bias toward judging the comparison interval as longer. Thus, these data imply that the timing of an empty interval may actually begin at the onset of the first marker and end at the offset of the second marker. Experiment 3 was designed to explore this issue with cross-modal intervals.

\section{Method}

Subjects. Five female Laurentian University students, 20 or 21 years old, participated in this experiment. They were paid $\$ 60$ (Canadian).

Apparatus and Stimuli. The stimuli and apparatus were the same as those in Experiment 2 with two exceptions. First, the duration of the first marker was now held constant at $5 \mathrm{msec}$. Second, the duration of the second marker was either 5 or $100 \mathrm{msec}$.

Procedure. The procedure was the same as that in Experiment 2 , but this time, the four marker conditions were $\mathrm{AV}_{5}, \mathrm{AV}_{100}, \mathrm{VA}_{5}$, and $\mathrm{VA}_{100}$. The subjects did not know before each trial if an AV or VA interval was going to be presented, nor did they know the duration of Marker 2. There were three standard durations: 250, 500, and $750 \mathrm{msec}$. The durations of the test stimuli were the same as those in Experiment 2.

\section{Results and Discussion}

Table 4 shows the individual and averaged difference thresholds for each condition. The overall results reveal that the difference thresholds increase as the base duration is increased for all but the $\mathrm{VA}_{5}$ condition. Also, when the $\mathrm{VA}_{5}$ condition is compared with the $\mathrm{AV}_{5}$ condition, and the $\mathrm{VA}_{100}$ condition is compared with the $\mathrm{AV}_{100}$ condition, acuity is better when the first signal is visual than when this signal is auditory, at least for the two longest base durations. These effects are similar to those obtained in the first two experiments. As before, the situation is more complex for the 250 -msec condition. In addition, there were large individual differences in this experiment. Subject 1 showed an extremely low difference threshold in both VA conditions at $750 \mathrm{msec}$. On the other end, Subject 4 had a very high difference threshold in both conditions where Marker 2 is $5 \mathrm{msec}$ for the 500 msec condition.
Those results were submitted to a $2 \times 2 \times 3$ randomized factorial block ANOVA. The only significant main effect was for duration $[F(2,44)=3.69, p<.05]$. This finding is consistent with the results of Experiments $1-2$ and with those reported by Rousseau et al. (1983) for AV intervals. None of the interactions were significant.

That the AV versus VA effect was not significant in Experiment 3 can be attributed to the large variability between subjects. Indeed, the differences between the means for similar conditions (same marker length and one given duration) are comparable to those in Experiment 2. Moreover, the general pattern of results parallels those observed in Experiments 1-2: superior discrimination in VA at 500 and $750 \mathrm{msec}$, but not at $250 \mathrm{msec}$.

The individual and mean PSE are also reported in Table 4. As in Experiment 2, the results show an important difference between the AV and VA conditions, with the former yielding lower PSE. In addition, the length of Marker 2 also seemed to influence perceived duration. However, in contrast to Experiment 2, the PSE are larger in the $\mathrm{AV}_{100}$ than in the $\mathrm{AV}_{5}$ condition for all three durations. In other words, the nature of the effect on PSE was not the same in both experiments.

Using transformed scores (PSE-standard interval), the statistical analyses revealed a significant effect for marker order $[F(1,44)=46.27]$ and marker length $[F(1,44)=$ $15.93, p<.01]$. The duration effect was not significant $[F(2,33)=1.03, p=.367]$, nor were any of the interactions.

In a replication of the findings of Experiment 2, AV intervals were perceived as longer than were VA intervals. This result is in accord with the hypothesis that the internal representation of a cross-modal interval is related to the times required to detect changes (either in the onset or in the offset) of auditory and visual signals.

More intriguing is the novel finding that the PSEs were strongly affected by variations in the duration of the marker terminating the interval. Increasing the duration of this marker increased perceived duration. This effect

Table 4

Differential Threshold (DT) and Point of Subjective Equality (PSE) Under Each Experimental Condition of Experiment 3

\begin{tabular}{|c|c|c|c|c|c|c|c|c|c|c|c|c|c|}
\hline \multirow[b]{3}{*}{ Subject } & & \multicolumn{6}{|c|}{ Auditory-Visual } & \multicolumn{6}{|c|}{ Visual-Auditory } \\
\hline & & \multicolumn{3}{|c|}{5} & \multicolumn{3}{|c|}{100} & \multicolumn{3}{|c|}{5} & \multicolumn{3}{|c|}{100} \\
\hline & & 250 & 500 & 750 & 250 & 500 & 750 & 250 & 500 & 750 & 250 & 500 & 750 \\
\hline \multirow[t]{2}{*}{1} & $\mathrm{DT}$ & 45 & 54 & 58 & 63 & 70 & 68 & 58 & 47 & 21 & 47 & 62 & 22 \\
\hline & PSE & 285 & 532 & 762 & 114 & 351 & 717 & 298 & 530 & 744 & 231 & 505 & 743 \\
\hline \multirow[t]{2}{*}{2} & DT & 61 & 76 & 74 & 78 & 71 & 118 & 57 & 48 & 70 & $5 l$ & 55 & 73 \\
\hline & PSE & 221 & 495 & 764 & 166 & 478 & 676 & 332 & 524 & 856 & 293 & 495 & 749 \\
\hline \multirow[t]{2}{*}{3} & DT & 90 & 50 & 67 & 84 & 43 & 66 & 160 & 48 & 68 & 87 & 46 & 66 \\
\hline & PSE & 221 & 519 & 742 & 168 & 495 & 711 & 364 & 532 & 771 & 348 & 504 & 773 \\
\hline \multirow[t]{2}{*}{4} & DT & 47 & 291 & 242 & 57 & 100 & 276 & 89 & 249 & 147 & 113 & 165 & 179 \\
\hline & PSE & 253 & 374 & 755 & 223 & 402 & 541 & 353 & 703 & 829 & 265 & 568 & 772 \\
\hline \multirow[t]{4}{*}{5} & DT & 74 & 137 & 185 & 68 & 199 & 156 & 86 & 119 & 137 & 62 & 91 & 147 \\
\hline & PSE & 217 & 417 & 707 & 221 & 345 & 692 & 341 & 527 & 732 & 293 & 527 & 753 \\
\hline & Mean DT & 63 & 122 & 125 & 70 & 96 & 137 & 90 & 102 & 89 & 72 & 84 & 97 \\
\hline & Mean PSE & 239 & 468 & 746 & 178 & 414 & 668 & 338 & 563 & 787 & 286 & 520 & 758 \\
\hline
\end{tabular}

Note-All values are in milliseconds. 
is not modality dependent: It was comparable for both $\mathrm{AV}$ and VA intervals. Averaged over the two marker orders, increasing the length of Marker 2 to $100 \mathrm{msec}$ produced decreases in the PSE of 56, 48, and $54 \mathrm{msec}$, for the 250-, 500-, and 750-msec conditions, respectively. The effect of marker length on PSE is not consistent with the hypothesis that timing stops following detection of the onset of Marker 2. Moreover, the larger PSEs (shorter internal intervals) did not result in lower difference thresholds.

\section{GENERAL DISCUSSION}

The results of these experiments provide some important insights into how people perceive intermodal intervals. First, in Experiment 1, we found that the visual intensity of a marker did not affect acuity of intermodal intervals. Second, in all three experiments, difference thresholds were generally lower with VA intervals than with $\mathrm{AV}$ intervals. This order effect, however, was most evident for the 500- and $750-\mathrm{msec}$ conditions, a conclusion supported by the significant order $\times$ duration interaction in Experiment 2. The order effect was not reliable in Experiment 3, where the length of Marker 2 was randomized, but the means were in the same direction.

Turning to the perceived duration data, both Experiments 2 and 3 showed that the VA intervals were perceived as shorter than were AV intervals of identical duration. In Experiment 2, there was also an effect of the Marker 1 length. Increasing the length of Marker 1 increased the perceived duration of the interval. This effect interacted with marker order, with the variation in the length of the initial marker affecting only perceived duration in the VA condition. In Experiment 3, the length of Marker 2 was also shown to contribute to the perceived duration of an interval. Again, increasing the duration of the marker led to an increase in perceived duration. In contrast to the findings of Experiment 2, this factor did not interact with marker order, affecting both $\mathrm{AV}$ and VA intervals to a comparable degree.

These effects were analyzed within the context of an internal-marker hypothesis (Grondin, 1993). This framework was initially developed to account for differences observed in the perception of filled and empty intervals. For empty intervals, this hypothesis assumes that the timing of the empty interval is initiated when the sensory trace of the first marker fades below some threshold and terminates when the second marker is detected (an offsetonset hypothesis). Conversely, the internal representation of a filled interval involves the detection of first the onset, and then the offset of the signal. Assuming the detection of the stimulus onset is faster than detection of the offset, the internal representation of a filled interval is longer than that of an empty interval.

A similar logic can be applied to cross-modal timing. Since visual signals have longer persistence and auditory signals are detected faster, the internal representation of a VA interval should be shorter than the internal representation of an AV interval of identical duration. Given
Weber's law for time perception, the difference threshold would be expected to be lower for the interval that is perceived to be shorter in duration. While this hypothesis can account for many features of the current data, there are some discrepant results. First, varying the length of the initial marker led to reliable changes in PSE, but did not influence the difference thresholds in Experiment 2. Second, the fact that increasing the length of either the first or second marker changed perceived duration is at odds with an offset-onset hypothesis.

One account for the effects found when Marker 1 was lengthened can be derived from the literature on the temporal integration and segregation of brief visual signals (Di Lollo, Hogben, \& Dixon, 1994; Efron, 1970; for reviews, see Nisly \& Wasserman, 1989; Patterson, 1990). Two brief consecutive visual stimuli can be perceived as a unitary configuration if the interstimulus interval is too short. This can be explained by the fact that the first signal remains visible for a brief period. Counterintuitively, a longer stimulus does not produce longer persistence but rather, shorter persistence (Di Lollo et al., 1994). The shorter persistence of a longer visual signal may account for the effect observed in Experiment 2 of a longer perceived duration. Indeed, marker length interacts with marker order: The increase of the perceived duration (lower PSE) with longer signals is most prominent when the first signal is visual (Figure 2).

The effect of marker length was minimal $(16.7 \mathrm{msec})$ when the first marker consisted of an auditory stimulus. This is considerably less than the 95 -msec effect one would predict if the internal timing started with the detection of the first marker (onset-onset hypothesis). In fact, even in the VA condition, the difference in PSE was under $60 \mathrm{msec}$. However, Woodrow (1928) argued for an onset-onset hypothesis to account for the internal representation of intramodal, auditory intervals. Further research is needed to determine the appropriate markings of intra- and intermodal intervals.

Both an offset-onset and onset-onset hypotheses assume that the timing of an empty interval is terminated when the second marker is detected. On the basis of this, we did not expect perceived duration to be affected by an increase in the length of the second marker. However, the results of Experiment 3 showed a consistent and substantial increase in perceived duration when the second marker was $100 \mathrm{msec}$ in duration compared with conditions in which the second marker was $5 \mathrm{msec}$ in duration.

A simple way to account for the effects of Marker 2 duration would be to assume that the timing stops at the offset of the signal. The problem we meet here is that the change in the PSE when Marker 2 was increased from 5 to $100 \mathrm{msec}$ was considerably less than $95 \mathrm{msec}$. On the other hand, Nakajima (1987) has suggested that the timing is not immediately terminated with the onset of the second marker of an empty interval, but after an approximate period of $80 \mathrm{msec}$ necessary for the processing of the interval. One hypothesis to explain why there is an effect of marker length on the perceived durationbut that this effect is not $95 \mathrm{msec}$ long-is that the pro- 
cessing period of the interval is slightly delayed by the continuation of the signal when the marker length equals $100 \mathrm{msec}$.

The results of these experiments show that discrimination performance of intermodal intervals cannot be directly accounted for by perceived duration. This was demonstrated by contrasting the PSE and difference threshold results in Experiments 2-3. For example, in Experiment 3, varying the length of Marker 2 affected perceived duration, but did not affect the difference thresholds. Although the same line, while differences in perceived duration can account for the superior performance of VA intervals in comparison to AV intervals with long intervals, this logic does not work for the 250 msec condition.

The VA versus AV difference has two theoretical implications. First, it suggests that the growth of variance, as a function of time, is not the same in the AV and VA conditions. This fact is not consistent with a slope analysis such as the one reported by Ivry and Hazeltine (1995), or Rousseau et al. (1983, see Figure 3). This slope analysis specifies that there is a parallel growth of variance in timing for various marker conditions. An unequal growth of variance was also reported with conditions involving a tactile marker for durations ranging from 250 to $1,000 \mathrm{msec}$ (Grondin, 1994). For example, a tactile-auditory sequence is more difficult to discriminate than a tactile-tactile sequence at $250 \mathrm{msec}$, but not at $1,000 \mathrm{msec}$. More work on Weber's law for intermodal conditions for a large range of durations is required.

Second, this AV versus VA difference suggests a need to consider at least one additional source of variability. Assume that the internal timing starts when the first marker fades, and that the trace is longer with a visual signal than with an auditory signal. Determining the offset of a more persistent visual signal may lead to greater uncertainty for the subject. Indeed, detecting the offset might then become a matter of decision criteria (Penner, 1975). If this were so, the efficiency in discriminating short intervals would rely partly on the reliability of the criterion adopted in judging the end of the visual signal. Subjects having more problems in processing the visual marker when it is used as a first signal would then show better performance in the AV condition. Increasing the duration of the empty interval might attenuate any interfering effect produced by the second marker on the criteria adopted for the detection of the first signal.

One final alternative hypothesis of note is based on the work of Desmond and Moore (1991). In developing a computational model of the temporal properties of classically conditioned responses, these researchers have proposed that separate timing mechanisms are activated by the onset and offset of stimuli. This assumption is critical for accounting for two different types of associative learning, delay and trace conditioning, within the framework of a single model. Applied in the current context, the dual-timer hypothesis may help explain the observed effects on perceived duration following changes in the length of either the first or the second marker. When the first marker is lengthened, the temporal representation associated with the signal onset would be lengthened. When the second marker is lengthened, the temporal representation associated with the signal offsets would be lengthened. Thus, a dual-timer hypothesis would account for the most robust and unexpected findings in the present study: namely, that perceived duration increases when either marker of an empty interval is increased. ${ }^{5}$ Variability under a dual-timing model would reflect how the two representations are integrated.

The preceding discussion is not intended to provide a definitive case for a model of the temporal representations of intervals marked by intermodal stimuli. Rather, we wish to suggest some potential mechanisms as a mean of guiding future research. While the focus here has been on how variations in sensory signals may affect access to an internal timing mechanism, it is important to keep in mind that intermodal intervals may disproportionately affect other processes involved in duration perception. For example, there may be additional attentional demands associated with shifting between modalities. More fundamentally, it remains to be established whether the perception of intramodal and intermodal intervals reflects the operation of a common timing mechanism. Building an empirical foundation regarding intermodal timing is essential for addressing these theoretical issues.

\section{REFERENCES}

ABEL, S. (1972). Discrimination of temporal gaps. Journal of the Acoustical Society of America, 52, 519-524.

Allan, L. G. (1979). The perception of time. Perception \& Psychophysics, 26, 340-354.

Allan, L. G., \& Kristofferson, A. B. (1974). Psychophysical theories of duration discrimination. Perception \& Psychophysics, 16, 2634.

Allan, L. G., Kristofferson, A. B., \& Wiens, E. W. (1971). Duration discrimination of brief light flashes. Perception \& Psychophysics, 9 , 327-334.

Carbotte, R. M., \& Kristofferson, A. B. (1973). On energy-dependent cues in duration discrimination. Perception \& Psychophysics, 14, 501-505.

Church, R. M. (1984). Properties of the internal clock. In J. Gibbon \& L. Allan (Eds.), Timing and time perception (Annals of the New York Academy of Sciences, Vol. 423, pp. 566-582). New York: New York Academy of Sciences.

COLLYER, C. E. (1974). The detection of a temporal gap between two disparate stimuli. Perception \& Psychophysics, 16, 96-100.

Creelman, C. D. (1962). Human discrimination of auditory duration. Journal of the Acoustical Society of America, 34, 582-593.

DESMOND, J. E., \& MoOre, J. W. (1991). Altering the synchrony of stimulus trace processing: Tests of a neural-network model. Biological Cybernetics, 65, 161-165.

Di Lollo, V., Hogben, J. H., \& Dixon, P. (1994). Temporal integration and segregation of brief visual stimuli: Patterns of correlation in time. Perception \& Psychophysics, 55, 373-386.

Divenyi, P. L., \& DanNeR, W. F. (1977). Discrimination of time intervals marked by brief acoustic pulses of various intensities and spectra. Perception \& Psychophysics, 21, 125-142.

Divenyl, P. L., \& SAChS, R. M. (1978). Discrimination of time intervals bounded by tone bursts. Perception \& Psychophysics, 24, $429-$ 436. 
EFron, R. (1970). Effect of stimulus duration on perceptual onset and offset latencies. Perception \& Psychophysics, 8, 231-234.

EKMAN, G. (1959). Weber's law and the related functions. Journal of Psychology, 47, 343-352.

Fetterman, J. G., \& KilleEN, P. R. (1992). Time discrimination in Columba livia and Homo sapiens. Journal of Experimental Psychology: Animal Behavior Processes, 18, 80-94.

Fraisse, P. (1952). La perception de la durée comme organisation du successif [The perception of duration as an organization of successive events]. Année Psychologique, 52, 39-46.

GIRAY, M., \& UlRICH, R. (1993). Motor coactivation revealed by response force in divided and focused attention. Journal of Experimental Psychology: Human Perception \& Performance, 19, 1278 1291.

GRONDIN, S. (1993). Duration discrimination of empty and filled intervals marked by auditory and visual signals. Perception \& Psychophysics, 54, 383-394

Grondin, S. (1994). About the influence of the sensory modes on duration discrimination. In L. M. Ward (Ed.), Fechner Day 94: Proceedings of the I0th Annual Meeting of the International Society for Psychophysics (pp. 42-47), Vancouver.

Grondin, S., \& Metrhé, L. (1993). Procedural effects on duration discrimination. In A. Garriga-Trillo, P. Minon, C. Garcia-Gallego, P. Lubin. J. Merino, \& A. Villarino (Eds.), Fechner Day 93: Proceedings of the Ninth Annual Meeting of the International Society for Psychophysics (pp. 107-112), Palma de Mallorca, Spain.

Grondin, S., \& Rousseau, R. (1991). Judging the relative duration of multimodal short empty time intervals. Perception \& Psychophysics, 49, 245-256.

IVRY, R. B. (1993). Cerebellar involvement in the explicit representation of temporal information. In P. Tallal, A. Gallaburda, R. R. Llinas, \& C. von Euler (Eds.), Temporal information processing in the nervous system: Special reference to dyslexia and dysphasia (Annals of the New York Academy of Sciences, Vol. 682, pp. 214-230). New York: New York Academy of Sciences.

IVRY, R. B., \& HAZELTINe, R. E. (1995). Perception and production of temporal intervals across a range of durations: Evidence for a common timing mechanism. Journal of Experimental Psychology: Human Perception \& Performance, 21, 3-18.

KaERNBACH, C. (1991). Simple adaptive testing with the weighted updown method. Perception \& Psychophysics, 49, 227-229

KeELE, S. W. (1986). Motor control. In K. R. Boff, L. Kaufman, \& J. P. Thomas (Eds.), Handbook of perception and human performance (Vol. 2, pp. 30-1 to 30-60). Toronto: Wiley.

KeELE, S. W., \& Ivry, R. B. (1991). Does the cerebellum provide a common computation for diverse tasks? In A. Diamond (Ed.), The development and neural bases of higher cognitive functions (Annals of the New York Academy of Sciences, Vol. 608, pp. 179-211). New York: New York Academy of Sciences.

KilleEn, P. R., \& Weiss, N. A. (1987). Optimal timing and the Weber function. Psychological Review, 94, 455-468.

KIRK, R. E. (1982). Experimental design: Procedures for the behavioral sciences. Belmont, CA: Brooks/Cole.

Nakajima, Y. (1987). A model of empty duration perception. Perception, 16, 485-520.

Nilsson, T. H. (1969). Two-pulse interval vision thresholds. Journal of the Optical Society of America, 59, 753-756.

NiSLY, S. J., \& WASSERMAN, G, S. (1989). Intensity dependence of perceived duration: Data, theories, and neural integration. Psychological Bulletin, 106, 483-496.

Patterson, R. (1990). Perceptual moment models revisited. In R. A. Block (Ed.), Cognitive models of psychological time (pp. 85-100). Hillsdale, NJ: Erlbaum.

Penner, M. J. (1975). The perception of offset: A problem of decision criteria. Perception \& Psychophysics, 17, 587-590.

PENNER, M. J. (1976). The effect of marker variability on the discrimination of temporal intervals. Perception \& Psychophysics, 19, 466469

RAMMSAYER, T. H. (1992a). Effects of marker duration on temporal information processing of empty intervals. In G. Borg \& G. Neely
(Eds.), Fechner Day 92: Proceedings of the Eighth Annual Meeting of the International Society for Psychophysics (pp. 165-170), Stockholm.

RAMmSAYER, T. H. (1992b). An experimental comparison of the weighted up-down method and the transformed up-down method. Bulletin of the Psychonomic Society, 30, 425-427.

RAMMSAYER, T. H. (1994). Effects of practice and signal energy on duration discrimination of brief auditory intervals. Perception \& Psychophysics, 55, 454-464.

RousSEAU, R., \& KRISTOFFERSON, A. B. (1973), The discrimination of binaural temporal gaps. Bulletin of the Psychonomic Society, 1, 115-116.

Rousseau, R., Poirier, J., \& Lemyre, L. (1983). Duration discrimination of empty time intervals marked by intermodal pulses. Perception \& Psychophysics, 34, 54l-548.

Tallal, P., Miller, S., \& Fitch, R. H. (1993). Neurobiological basis of speech: A case for the preeminence of temporal processing. In P. Tallal, A. M. Galaburda, R. R. Llinas, \& C. von Euler (Eds.), Temporal information processing in the nervous system: Special reference to dyslexia and dysphasia (Annals of the New York Academy of Sciences, Vol. 682, pp. 27-47). New York: New York Academy of Sciences.

TREISMAN, M. (1963). Temporal discrimination and the indifference interval: Implications for a model of the "internal clock." Psychological Monographs, 77(Whole No. 576).

Woodrow, H. (1928). Behavior with respect to short temporal stimulus forms. Journal of Experimental Psychology, 11, 167-198.

\section{NoTES}

1. To verify that there were behavioral effects associated with the different intensities, we collected simple reaction time data as part of a pilot study. In this study, three levels of visual intensity were compared for AV and VA intervals of $250 \mathrm{msec}$. Two were the high- and lowintensity signals of Experiment 1 (2.1 and $0.8 \mathrm{~mA}$, respectively). The third was of very high intensity $(12.2 \mathrm{~mA})$. The levels were selected on the basis of the judgments of three observers who were asked to select the "high-intensity" signal to be midway in brightness between that of the low and very high signals

The mean reaction times to the each type of signal in isolation (with catch trials) were 221,213 , and $200 \mathrm{msec}$ for the low-, high-, and very high-intensity signals. The mean simple reaction to the auditory tone was $147 \mathrm{msec}$. The large difference between the auditory and visual signals is consistent with previous reports (Giray \& Ulrich, 1993; Keele, 1986). We did not use the very high-intensity signal in Experiment 1 because it was associated with larger variability on time perception tasks in a pilot study.

2. There was no standard in the traditional sense since we used the many-to-few method. What is called a standard in Experiments $2-3$ is indeed an implicit standard, which is the midpoint value of the intervals to be discriminated.

3. Since there was no presentation of a standard for each trial, the term point of subjective equality (PSE) cannot be understood here in its traditional sense. It is used as an index, in Experiments 2-3, for comparing the relative equality of the different marker conditions. Some readers might prefer the term bisection point to PSE.

4. For the perceived duration in Experiments 2-3, the statistical analysis was conducted on the basis of the deviation of the PSE from the impiicit standard intervals. In the traditional use of the method of constant stimuli, where a standard is presented on each trial, the term constant error is used to express the difference between the PSE and the standard.

5. This model could also account for why subjects show greater acuity with unfilled intervals than with filled intervals. Whereas unfilled intervals yield two representations, one tied to the onset and one tied to the offsets, a single representation, mixed from an onset trigger and offset terminator, is required for filled intervals.

(Manuscript received May 20, 1994: revision accepted for publication August 18, 1995.) 